\title{
Male pubertal development: are endocrine-disrupting compounds shifting the norms?
}

\author{
William Zawatski' and Mary M Lee
}

Pediatric Endocrine Division, 'Department of Pediatrics, University of Massachusetts Medical School, 55 Lake Avenue North, Worcester, Massachusetts 01655, USA
Correspondence should be addressed to $\mathrm{M} M$ Lee Email mary.lee@umassmemorial.org

\begin{abstract}
Endocrine-disrupting compounds (EDCs) are synthetic or natural compounds that interfere with endogenous endocrine action. The frequent use of chemicals with endocrine active properties in household products and contamination of soil, water, and food sources by persistent chemical pollutants result in ubiquitous exposures. Wildlife observations and animal toxicological studies reveal adverse effects of EDCs on reproductive health. In humans, a growing number of epidemiological studies report an association with altered pubertal timing and progression. While these data are primarily reported in females, this review will focus on the small number of studies performed in males that report an association of polychlorinated biphenyls with earlier sexual maturity rating and confirm subtle effects of lead, dioxins, and endosulfan on delaying pubertal onset and progression in boys. Recent studies have also demonstrated that EDC exposure may affect pubertal testosterone production without having a noticeable effect on sexual maturity rating. A limitation to understand the effects of EDCs in humans is the potential for confounding due to the long temporal lag from early-life exposures to adult outcomes. The complex interplay of multiple environmental exposures over time also complicates the interpretation of human studies. These studies have identified critical windows of vulnerability during development when exposures to EDCs alter critical pathways and affect postnatal reproductive health. Contemporaneous exposures can also disrupt the hypothalamic-pituitary-gonadal axis. This paper will review the normal process of puberty in males and summarize human data that suggest potential perturbations in pubertal onset and tempo with early-life exposures to EDCs.
\end{abstract}

Journal of Endocrinology (2013) 218, R1-R12

\section{Introduction}

While earlier onset of thelarche and pubarche in females has been consistently observed in recent decades (Euling et al. 2008a), the trends in male pubertal timing are less clear. Some studies report an earlier age of onset for pubic hair and testicular development in males, whereas others dispute such temporal shifts (Euling et al. 2008a). An important contributor to the secular trend in female pubertal timing is the significant improvement in overall public health over the past century. Multiple reports, however, also emphasize the potential role of environmental chemicals, specifically endocrine-disrupting compounds (EDCs; Acerini \& Hughes 2006, Euling et al. 2008b, Mouritsen et al. 2010, Toppari \& Juul 2010). EDCs are hormonally active compounds that are speculated to 
have a causative role in the recent decline in sperm counts and impaired fertility worldwide, as well as the regionspecific changes in the prevalence of hypospadias and cryptorchidism, and reproductive tract cancers (Sharpe \& Skakkebaek 1993). This review explains pubertal development in males, summarizes the reproductive effects of EDCs in animal models and their connection to human health, and reviews the available human data relating to EDC exposure and male pubertal timing.

\section{Male pubertal development}

Puberty is an important parameter of reproductive health, marking the sexual maturation of the hypothalamicpituitary-gonadal (HPG) axis that culminates in adult hormonal profiles and physical changes that are essential for reproductive fitness. The reawakening of the HPG axis stimulates gonadal sex steroid production, which leads to development of secondary sexual characteristics, accelerated growth, and achievement of fertility. Pubertal status and progression are evaluated using a sexual maturity scale developed by Tanner and now adopted widely (Marshall \& Tanner 1970).

The GNRH pulse generator and the HPG axis are functional by the end of the first trimester of gestation (Grumbach 2002). After birth, the HPG axis is active until $\sim 6$ months of life, with gonadotropin and sex steroid concentrations peaking between 4 and 12 weeks of life (Forest et al. 1973, Anderson et al. 2003), representing the 'mini-puberty' of infancy. Subsequently, GNRH pulsatility is markedly reduced and the HPG axis is relatively quiescent throughout childhood. Onset of puberty is characterized by

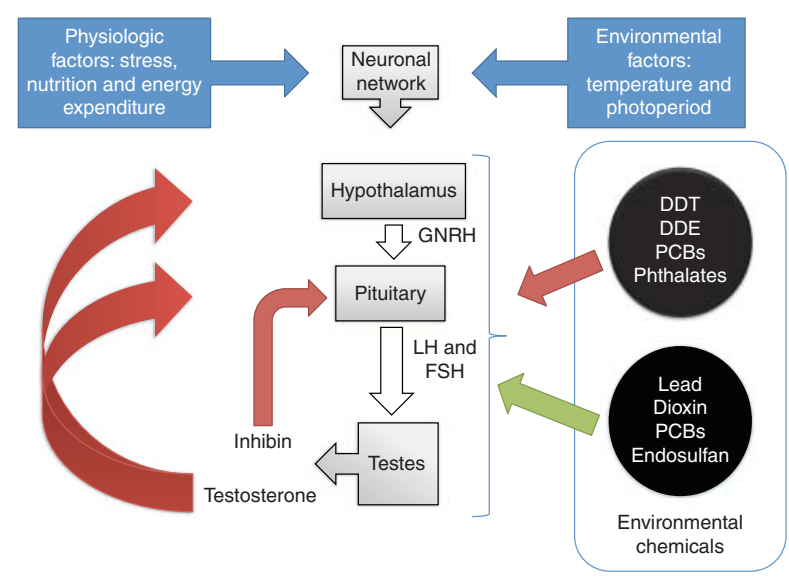

Figure 1

Schematic of the HPG axis and the potential endocrine targets for EDC perturbation of puberty. pulsatile GNRH release from the hypothalamus that stimulates pituitary LH secretion, which in turn drives testosterone production by testicular Leydig cells (see Fig. 1). Short bursts of LH release occur nocturnally early in puberty, accompanied by nighttime elevations in serum testosterone. GNRH also increases FSH secretion, which promotes maturation of the seminiferous tubules and spermatogonia. Serum concentrations of $\mathrm{LH}$, testosterone, and inhibin $\mathrm{B}$ are positively associated with age and pubertal progression (Anderson et al. 2003, Crofton et al. 2004). A large, crosssectional study measured $\mathrm{LH}$, testosterone, and inhibin B levels in 828 boys aged $6-11$ years in an effort to understand the relationship between hormone concentrations and pubertal staging (Lee et al. 2010b). The increment in LH and testosterone concentrations was greatest from ages 9 through 11 years, whereas a progressive rise in serum inhibin B was seen from age 6 years onward. While these hormones increase with advancing age and progressive pubic hair and genital stages, individual hormone levels significantly overlap between Tanner stages, making it difficult to establish distinct criteria to delineate pubertal onset and stages (Fig. 2). For example, while the mean testosterone values increase from 0.87 to $0.97 \mathrm{nmol} / \mathrm{l}$ in genital stage 1 vs 2 , the confidence limits overlap extensively (0.67-1.07 for stage 1 vs $0.76-1.25$ for stage 2 ; Lee et al. 2010b).

The critical determinants of pubertal activation of the HPG axis have not been fully identified, but somatic growth, body fat, diet, stress, photoperiod, circadian rhythm, gonadal steroids, energy expenditure, and olfactory cues influence the neuronal network to modulate pubertal onset (Ebling 2005). Kisspeptins are a family of peptides encoded by the KISS1 gene on chromosome 1q32 that bind to GPR54 (KiSS-1 receptor), a member of the rhodopsin family of G-protein-coupled receptors (reviewed in Roseweir \& Millar (2009) and Kauffman (2010)). Kisspeptin is produced as a 145 amino acid propeptide that is cleaved to generate the bioactive kisspeptin-54. Analysis of expression reveals that KiSS-1 axon terminals densely innervate the infundibular stalk and lamina terminalis in the hypothalamus while KiSS-1-ir axon varicosities are found in a number of hypothalamic regions, including the ventral periventricular, supraoptic, preoptic, paraventricular, and infundibular nuclei. KiSS-1-ir fibers are also present in the ventromedial and dorsomedial hypothalamus, the medial septum, and stria terminalis. KiSS-1 and GNRH have overlapping expression in circumventricular organs, and KiSS-1-containing axon varicosities are contiguous to GNRH neuronal dendrites, while GPR54 is expressed on GNRH neurons as well as in

Published by Bioscientifica Ltd. 

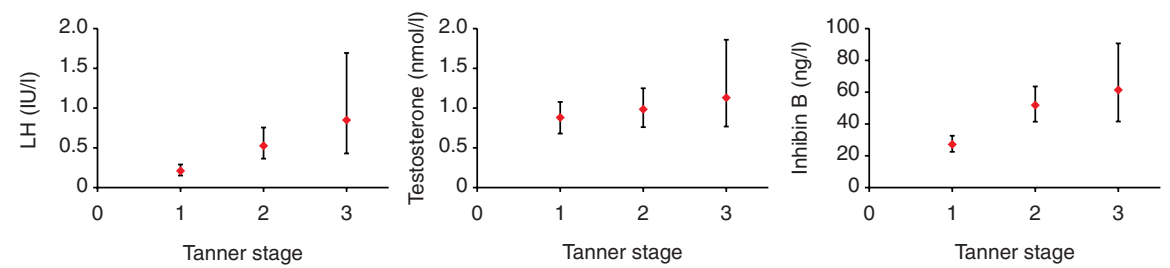

Figure 2

Graph of changes in $\mathrm{LH}$, testosterone, and inhibin values during genital stages 1, 2, and 3. Mean and 95\% confidence limits are depicted (generated with permission using data in Table 2 from Lee PA, Gollenberg AL, Hediger ML, Himes JH, Zhang Z \& Louis GM 2010b Luteinizing hormone,

the adenohypophysis (Oakley et al. 2009). The intimate connection between neurons expressing KiSS-1 and GNRH, established via KiSS-1 binding to GPR54, supports the crucial role of the kisspeptin/GPR54 ligand receptor complex in pubertal activation of the HPG axis.

Hypothalamic expression of KISS1 and GPR54 mRNA increases in rodents and primates as puberty progresses (Roseweir \& Millar 2009, Ojeda et al. 2010). In addition, the greater number of GNRH neurons depolarized by KISS1 during puberty in the mouse is thought to be due to increased GPR54 sensitivity to KISS1 and apposition of KISS1 and GNRH neurons (Roseweir \& Millar 2009). In male rhesus monkeys, mRNA expression of KISS1 but not GPR54 increases with pubertal progression, suggesting that the ligand is the primary regulatory factor. Studies in juvenile female rats and nonhuman primates demonstrate that repetitive administration of exogenous KISS1 is sufficient to initiate puberty. GNRH antagonists inhibit pubertal maturation in this model, suggesting that this process is mediated through KISS1 stimulation of GNRH secretion. These recent studies confirm that KISS1/GPR54 function is critical in activating pulsatile GNRH release at the onset of puberty. Kisspeptins integrate nutritional and environmental signals and have a central role in stimulating GNRH release along with glutamate, neurokinin B, and growth factors released by glial cells (Oakley et al. 2009, Roseweir \& Millar 2009, Kauffman 2010, Ojeda et al. 2010). GABAergic and opiatergic neurons tonically inhibit the release of GNRH (Terasawa \& Fernandez 2001, Ojeda et al. 2010). Thus, an intricate network of neuronal and glial cells exerts a balance of excitatory and inhibitory actions on hypothalamic release of GNRH to promote onset of puberty (Ojeda et al. 2010).

Puberty encompasses both gonadarche and adrenarche, two independently controlled processes. Adrenarche occurs with maturation of the adrenal zona reticularis and upregulation of 17,20-lyase and 17 $\alpha$-hydroxylase activity, which results in increased production of the adrenal testosterone and inhibin B levels in the peripubertal period and racial/ethnic differences among boys aged 6-11 years: analyses from NHANES III, 1988-1994. Clinical Endocrinology 73 744-751).

androgens, DHEA, DHEAS, and androstenedione. The adrenal androgens start to increase at ages 6-8 years, 2 or more years before gonadarche, and are responsible for the mid-childhood growth spurt and initial stages of pubic hair growth. Pubic hair distribution progresses with puberty, beginning with pigmented hair at the base of the penis with eventual spread to the medial thighs and linea alba. Axillary hair is usually first noticeable in mid-puberty, followed by hair growth in other androgen-sensitive areas, including the chest, upper back, abdomen, and upper thighs. Acne, oily skin, deepened voice, and adult-type body odor are also adrenal androgen-mediated effects. Linear growth starts to accelerate at genital and pubic hair stage 2 in males (Tanner 1985 ) and reaches a peak growth velocity of $\sim 9.5 \mathrm{~cm} /$ year during later stages of puberty (stages 3-4) and a testicular volume of 10-12 cc (Bordini \& Rosenfield 2011). As skeletal growth and maturation occur, lean body mass as well as relative proportions of water, muscle, and bone also increase (Rogol 2010). These physical changes are mediated by sex steroids, GH, thyroid hormone, genetics, and physical activity.

Gonadarche follows the increased GNRH pulsatility and subsequent rise in $\mathrm{LH}$ and FSH secretion. In addition to absolute increases in $\mathrm{LH}$ and $\mathrm{FSH}$, an $\mathrm{LH}$ :FSH ratio $>1$ suggests puberty. In males, the first physical change is an increase in testicular volume $(\geq 3 \mathrm{cc}$ ) and longitudinal axis $(\geq 2.5 \mathrm{~cm})$. This early increase in testicular size is due to FSH-mediated growth of seminiferous tubules. As testosterone is produced, enlargement and rugation of the scrotum occur along with testicular enlargement. As puberty progresses, the testes, scrotum, and penis continue to enlarge until they reach adult size and shape. Spermarche occurs during mid-puberty, after significant stimulation by gonadotropins and testosterone (Nielsen et al. 1986). Adult morphology, motility, and concentration of sperm are not achieved until near sexual maturity (Kulin et al. 1989). During stages 3-4 of pubertal development, adolescent gynecomastia occurs in $\sim 50 \%$ of

Published by Bioscientifica Ltd. 
males (Biro et al. 1990). The breast tissue usually regresses within 1 year, but may persist longer in obese males. Those with Klinefelter syndrome or partial androgen resistance typically have permanent gynecomastia.

Much debate surrounds the validity and reliability of population studies evaluating genital staging and timing of puberty, as most studies use visual inspection or self-reported pubertal status without directly assessing testicular volume (Walvoord 2010). The secular trend of a decreasing age of puberty during the 19th and early 20th century is most likely due to improved nutrition and sanitation and public health infection control (Walvoord 2010). There remains debate as to whether this secular trend has continued in the past half century in boys as described in girls (Herman-Giddens et al. 1997, Euling et al. 2008a). The first national survey that included data on male pubertal onset was the National Health Examination Survey III (NHES III), conducted between 1966 and 1970 in 3130 children aged $12-17$ years (Harlan et al. 1979). The Hispanic Health and Nutrition Examination Survey (HHANES), conducted from 1982 to 1984, also assessed pubertal development, although only among Hispanic Americans 10-18 years of age. The National Health and Nutrition Examination Survey III (NHANES III, 1988-1994) examined 2114 children aged 8-19 years and estimated the median age at entry of Tanner 2 genitalia stage at 10.3, 10, and 9.2 years for Hispanic, white, and black males respectively by visual inspection (HermanGiddens et al. 2001). Using data from these three studies (1966-1994), Sun et al. (2005) concluded that the onset of puberty and progression to mid-puberty are occurring at an earlier age for white males and Hispanic males but not for non-Hispanic black males. The age of attainment of sexual maturity among these groups, however, is unchanged and even later for non-Hispanic white boys. Other groups compared data from the Bogalusa Heart Study and NHANES III and noted a trend toward an earlier age of the male pubertal growth spurt, which supports an earlier age of pubertal onset and pace (Karpati et al. 2002).

Researchers in Denmark examined the secular trend in pubertal onset using rigorous assessment tools that include testicular volume measurement and gonadotropin and sex steroid measurements (Sorensen et al. 2012). The study design also included comparisons of Danish males from the same communities, studied 15 years apart, 1991-1993 and 2006-2008. Puberty began 3 months earlier for males in the latter group, although this was not significant when the results were corrected for BMI. In addition, LH levels were higher in the latter group, which investigators attribute to the effects of obesity and/or influence of endocrine disruptors. By contrast, USA data suggest that increased BMI is associated with pubertal delay in males rather than earlier onset (Lee et al. 2010a).

An expert panel reviewed the studies on pubertal timing from 1940 to 1994 to ascertain whether a secular trend exists during this time period (Euling et al. 2008a). One of the complexities in comparing different studies is that pubertal milestones are not as easily identified in boys and therefore methodology varied from reliance upon visual inspection of staging to the use of surrogate measures such as voice change or attainment of adult height as endpoints associated with sexual maturation (Rockett et al. 2004). Most studies lacked measurement of testicular volume, which is the most reliable method of assessing pubertal onset and progression. The panel concluded that data on male puberty were insufficient to confirm a secular trend toward earlier puberty. This is largely due to the paucity of data on male pubertal trends as well as concerns regarding data quality among existing studies. Nevertheless, animal studies suggest that exposure to EDCs perturb reproductive development and fertility. Recently, epidemiological studies are starting to report associations of gestational or childhood exposures with pubertal onset or progression and other disorders of the reproductive system in males (Nebesio \& Pescovitz 2005, Euling et al. 2008b, Schoeters et al. 2008, JacobsonDickman \& Lee 2009, Patisaul \& Adewale 2009, Mouritsen et al. 2010). Assessment of the role of EDCs on pubertal onset, however, is complicated by the significant contributions of genetics, nutrition, somatic growth, and overall health on pubertal timing. Nevertheless, a geographically based increase in the incidence of hypospadias, cryptorchidism, and testicular germ cell cancers has been observed, and sperm counts and fertility rates have declined worldwide raising concerns about environmental influences on male reproductive health (Sharpe \& Skakkebaek 1993, Acerini \& Hughes 2006). To explain these observations, the testicular dysgenesis syndrome has been proposed to hypothesize that fetal exposure to estrogenic chemicals during testicular development leads to long-term effects on male reproductive health (Sharpe \& Skakkebaek 1993).

\section{Endocrine-disrupting compounds}

The definition of an EDC was recently broadened by the Endocrine Society to include any compound that perturbs endocrine action (Zoeller et al. 2012). Many natural and synthetic compounds have activity in endocrine organs or

Published by Bioscientifica Ltd 
signaling pathways, but not all alter endocrine systems in ways that impair human health. During the last century, the abundance of synthetic chemicals developed for consumer products, and commercial industrial processes have raised significant concerns with respect to health effects (Diamanti-Kandarakis et al. 2009). Furthermore, organohalogens generated during industrial processes have also been a cause for concern. In 1962, Rachel Carson published Silent Spring, an account of the severe reproductive toxicity of pesticides in avian species (Carson 1962). This launched investigations into the role of chemicals as potential environmental toxins. These studies revealed that some chemicals exert detrimental effects due to their hormonal activity, thus the term 'EDCs' or 'endocrine disruptors' was coined. Examples include pharmacological compounds, such as diethylstilbestrol (DES), a synthetic estrogen, as well as industrial or agricultural chemicals such as plasticizers or insecticides. EDCs interfere with hormonal pathways through a multitude of mechanisms. They can compete for estrogen receptor binding and activation, interfere with post-receptor signaling pathways, and modulate synthesis, bioactivity, or degradation of hormones, receptors, and cofactors. Most EDCs are classified as xenoestrogens, whereas others inhibit androgen production and function. The aromatic hydrocarbons disrupt hormonal pathways by binding to the arylhydrocarbon receptor (AhR). Besides acute effects, EDCs can also interfere with developmental programming, during critical periods of embryogenesis, resulting in long-term effects on health.

Examples of synthetic EDCs are listed in Table 1. In addition, naturally occurring compounds such as soy phytoestrogens and lead, cadmium, and other heavy metals are also considered as EDCs. Several properties of industrial and pharmaceutical chemicals increase their toxicity. Lipophilic compounds bioaccumulate through the food chain and concentrate in adipose tissue. For some chemicals, the metabolized intermediary compound is even more toxic than the parent compound. Moreover, while chemical stability is a desirable characteristic for an industrial chemical, this results in compounds that are highly resistant to degradation and therefore termed 'persistent organic pollutants'. Indeed, with worldwide contamination of soil, air, and water, there is universal exposure to environmental chemicals, and concentrations in humans reach levels associated with animal toxicity.

The pharmacokinetics of EDCs demonstrates an atypical U-tonic dose-response curve for some chemicals, whereas others have an inverted U-tonic curve. Endpoints of EDC toxicity include both acute and latent effects (Schoeters et al. 2008, Toppari \& Juul 2010). Prenatal and neonatal periods are particularly susceptible to EDCs. Animal studies illustrate critical windows of susceptibility to EDCs during fetal life that involve epigenetic changes affecting metabolic and endocrine pathways (Dolinoy et al. 2007, Walker \& Gore 2011). Interestingly, these effects have been observed with doses considered to be below the lowest observable adverse effect level (Diamanti-Kandarakis et al. 2009). Interindividual and inter-species variation in susceptibility may be due to differences in pharmacokinetics (i.e. absorption, distribution, metabolism, and excretion) and/or genetic polymorphisms in key genes such as the AhR. In humans, the long interval from exposure to endpoints (favoring retrospective study design), difficulty in assessing internal exposures, and the setting of mixed exposures over a lifetime confound the analysis of the health effects of EDCs.

\section{EDCs and puberty in rodent models}

Animal studies demonstrate both central and peripheral mechanisms for interfering with puberty. Moreover, pubertal timing can be influenced by either prenatal or postnatal exposure to EDCs, depending on the compound and species. During early stages of CNS development and sexual differentiation, EDC exposure can disrupt many aspects of the HPG axis, from neuroendocrine organization and feedback loops to gonadal sex steroid synthesis (Navarro et al. 2009, Walker \& Gore 2011). In rodents, early exposure to sex steroids is crucial for appropriate Kiss1r mRNA expression (Tena-Sempere 2010). Sex steroids are also important for increased production of hypothalamic kisspeptins as puberty progresses. Synthetic estrogen exposure during critical periods in rodent development resulted in decreased hypothalamic Kiss1 mRNA expression and lack of GNRH activation and gonadotropin secretion. Administration of kisspeptin reverses the inhibition of pubertal activity by estrogen exposure, highlighting the potential for EDCs to perturb the kisspeptin system. EDC actions are often sexually dimorphic, with estrogenic compounds eliciting opposite effects in males and females. Some compounds generate divergent effects, with the dose and timing of administration during sexual development being particularly important. For example, prenatal exposure to genistein results in pubertal delay in female rats, whereas postnatal exposure results in premature puberty (Rasier et al. 2006, Dickerson \& Gore 2007).

Published by Bioscientifica Ltd 
Table 1 Endocrine-disrupting compounds

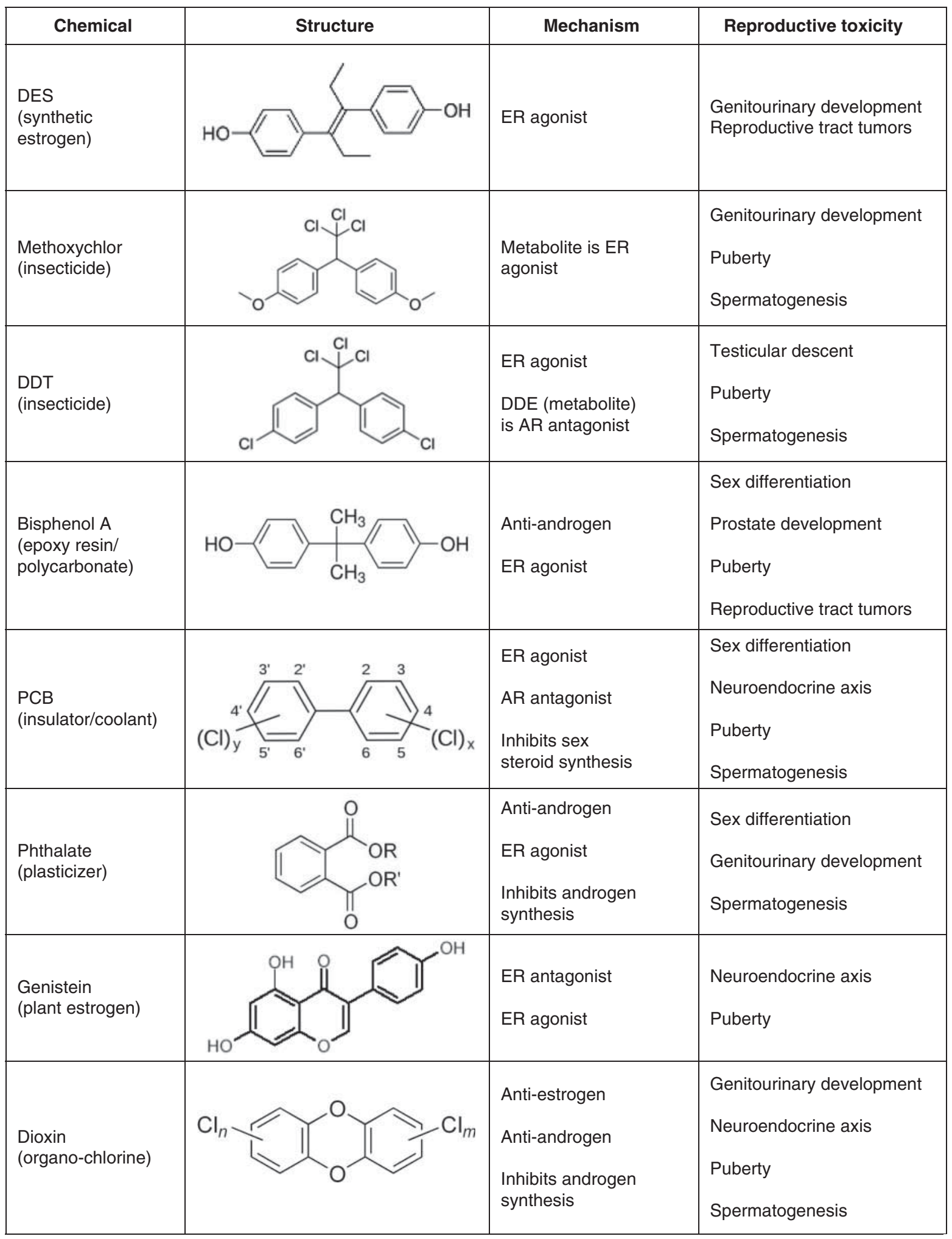

DES, diethylstilbestrol; DDT, dichlorodiphenyltrichloroethane; PCB, polychlorinated biphenyls; DDE, dichlorodiphenyldichloroethylene. 
Most compounds with weak estrogenic activity cause earlier onset and/or more rapid progression of puberty in females. Alternatively, a spectrum of effects may be observed in males exposed to compounds with estrogenic activity, from no noticeable effect to pubertal delay. Diethylhexylphthalate (DEHP), a phthalate plasticizer used in infant toys and medical tubing, is one of the few compounds associated with an earlier onset of male puberty. Ge et al. (2007) examined the effects of postnatal DEHP treatment on two measures of rat puberty: preputial separation (PPS), a rat correlate of male pubertal onset, and testicular steroidogenesis. In rats treated for 21 days after weaning with daily gavage DEHP $(10 \mathrm{mg} / \mathrm{kg})$, PPS occurred 2 days earlier and serum testosterone concentrations were higher than those in control rats. Higher doses $(750 \mathrm{mg} / \mathrm{kg})$ paradoxically caused a 5 -day delay in PPS and inhibited testosterone concentrations. The authors also showed that the rise in serum testosterone was not accompanied by any changes in pituitary LH mRNA expression, suggesting that the DEHP effects were probably mediated directly on the testosterone biosynthetic pathway rather than via the HPG axis. This dosedependent stimulatory effect of DEHP causing earlier pubertal onset has not been reported in males exposed to other EDCs.

Estrogenic chemicals generally delay pubertal onset in male rodents (Rasier et al. 2006, Dickerson \& Gore 2007). DES, a non-steroidal potent estrogen, is the classic compound first appreciated to cause adult reproductive toxicity in offspring exposed to DES in utero (Herbst et al. 1971). The different reproductive outcomes observed by shifting exposure windows for DES illustrate that a single compound may act via different mechanisms and that the dose-responses are nonlinear. Transplacental and lactational exposure to DES through weaning (PND21) causes a delay in two reproductive endpoints: descent of the testes and PPS. Exposure to DES through drinking water during the peripubertal and young adult time period (PND21100) results in a similar phenotype. By contrast, only descent of the testes is affected when the exposure window is restricted to the lactational period or if exposure is interrupted at PND10 and neither of these reproductive endpoints are observed with gestational exposures only (Odum et al. 2002). The nonlinear dose-response effects of DES are best illustrated with the postnatal treatment model. The highest dose tested by this group $(10 \mathrm{mg} / \mathrm{l})$ had no effect on either testicular descent or PPS while the intermediate dose of $60 \mu \mathrm{g} / \mathrm{l}$ resulted in a 2- to 3-day delay in testicular descent and a 5-day delay in PPS. Lowering the dose of DES to $30 \mu \mathrm{g} / 1$ reduced the PPS delay to 2 days
(Odum et al. 2002). The lack of effect on PPS timing with gestational exposures was also observed by Yoshimura et al. (2005). Shin et al. (2009) explored the dose effects of DES in a narrower postnatal treatment window (PND33-54) on male pubertal development and hormone profile. The lowest gavage dose of DES $(10 \mu \mathrm{g} / \mathrm{kg}$ per day) had no effect on PPS timing, whereas 20 and $40 \mu \mathrm{g} / \mathrm{kg}$ per day caused a delay in PPS. All three doses of DES delayed the pubertal increase in secretion of LH and testosterone and exerted dose-dependent inhibition of testicular weight and spermatogenesis. Others have shown similar effects of postnatal exposures to $\mathrm{p}, \mathrm{p}^{\prime}$-dichlorodiphenyldichloroethylene (DDE) and BPA on age of PPS as a measure of male reproductive developmental timing (Tan et al. 2003, Yoshimura et al. 2005). These studies led to the important observation that for DES and similar estrogenic compounds, gestational and early neonatal exposures had no effect on male pubertal measures. Postnatal exposure during the peripubertal and pubertal maturational processes, however, can perturb several processes associated with male sexual maturation.

By contrast, gestational exposure to polychlorinated biphenyls (PCB) mixtures and either gestational or lactational exposure to dioxins were associated with delayed PPS across species and strains, implicating different mechanisms of action for these compounds compared with the estrogenic chemicals described earlier. Chronic gestational exposure to 2,3,7,8-tetrachlorodibenzo-pdioxin (TCDD) through maternal diet also caused a delay in PPS (Bell et al. 2007). Gavage of a mixture of dioxins, furans, and non-ortho PCBs that reflects the relative ratio of these compounds in contaminated food products to Long Evans rats at GD15 caused a delay in PPS and decreased seminal vesicle weight (Hamm et al. 2003). A single injection of TCDD ( $1 \mathrm{mg} / \mathrm{kg}$ per dose) at GD15 decreased 17-hydroxylase activity and reduced epididymal weights in male offspring at PND30 (Cooke et al. 1998). Thus, in contrast to DES, for PCB and dioxins, the gestational window of exposure is critical for pubertal delay.

A number of synthetic chemicals and byproducts, such as vinclozolin, prochloraz, linuron, DEHP, and DDE, a metabolite of dichlorodiphenyltrichloroethane (DDT), have anti-androgenic properties in in vitro assays and have been tested in toxicology studies for pubertal endpoints. Two dicarboximide fungicides, vinclozolin and iprodione (IPRO), used for growing grapes, are androgen receptor antagonists in vitro. Gestational and neonatal treatment of Sprague Dawley rats with vinclozolin had no effect on the age of PPS, but later gavage treatment in pubertal rats caused a 2- to 3-day delay in the

Published by Bioscientifica Ltd. 
age of PPS (Monosson et al. 1999). In contrast to the delay in PPS timing, the vinclozolin treatment stimulated pituitary LH secretion and prevented normal sex steroidnegative feedback of the HPG axis. This resulted in increased testosterone production and therefore no change in the weights of androgen-responsive male reproductive structures. Other compounds such as lead, methoxychlor, styrene, and IPRO have also been associated with delayed onset of male puberty (Gray et al. 1989, Rasier et al. 2006, Dickerson \& Gore 2007, Durrer et al. 2007). Observations of reproductive toxicity in wildlife as well as insights from these and other animal exposure models confirm that pubertal-timing endpoints are sensitive to disruption by hormonally active compounds.

\section{EDCs and human puberty}

Humans are exposed to an array of environmental chemicals that exhibit estrogenic or anti-androgenic properties, with potential effects on pubertal development. Despite the bans on highly toxic compounds such as DDT and PCBs as well as efforts to reduce generation of hydrocarbons, these chemicals remain detectable in the environment. This is primarily due to their long half-lives, lipophilic nature, and propensity to bioaccumulate (Diamanti-Kandarakis et al. 2009). Consumption of contaminated fish, meats, and dairy products are a major source of exposure for humans. Human studies to date have focused on high exposures due to industrial accidents. Moreover, most studies have examined more easily assessed surrogate measures of reproductive maturation, such as timing of menarche or semen analysis; therefore, data on pubertal onset or tempo are limited.

Human studies have generally been small and flawed by incomplete exposure assessment and imprecise endpoints with respect to pubertal development. Early signs of pubertal onset and progression may only be detectable on a detailed physical examination, which is rarely performed in epidemiological studies (Rockett et al. 2004). Studies have attempted to use clinical surrogates such as peak growth velocity, but this occurs late in puberty and therefore may correlate with the tempo rather than the onset of puberty. Moreover, confounding exposures to multiple chemicals and the long latency period between exposure and effect make it difficult to draw firm conclusions about the effects of exposure to a single agent. Analysis of pubertal outcomes in epidemiological studies is also complicated by the confounding associations of overnutrition and BMI with pubertal timing and the difficulty in distinguishing the influence of nutrition and BMI from that of EDCs, particularly since foods are a common source of exposure. Nevertheless, the demonstration of associations between exposures and altered pubertal timing, together with supportive animal data, makes it reasonable to conclude that a relationship between EDCs and pubertal timing exists. Many studies report an earlier onset of puberty and faster progression in girls exposed to EDCs, while delayed puberty has been reported in both boys and girls. Several studies, however, have failed to find associations of organochlorine exposures with altered pubertal timing (Gladen et al. 2000, Leijs et al. 2008, Su et al. 2012). Phytoestrogens are plant-derived natural compounds with weak estrogenic activity that are present in soy. In young adult men fed soy formula as infants, no association has been found with pubertal onset or other reproductive outcomes (Strom et al. 2001).

\section{EDCS and earlier pubertal development}

Multiple studies have reported associations of environmental chemical exposures with early puberty in girls (Schoeters et al. 2008, Diamanti-Kandarakis et al. 2009, Jacobson-Dickman \& Lee 2009, Mouritsen et al. 2010, Toppari \& Juul 2010), and a large ongoing multicenter epidemiological study will prospectively explore the associations of childhood measured EDCs with pubertal onset (Biro et al. 2010, 2012). By contrast, the data in boys are limited and less convincing. Observations of a strikingly higher prevalence of precocious puberty in the Viareggio region compared with other areas in Italy (relative risk of 5.73) raised the concern of whether environmental factors were contributory (Massart et al. 2005). A Flemish study of 88714 - to 15 -year-old boys found a positive association of concurrent serum concentrations of hexachlorobenzene (HCB), DDE, and PCBs with pubertal development (Den Hond et al. 2010). In this study, a twofold increase in serum $\mathrm{HCB}$ and DDE concentrations was associated with an increased odds ratio of being in genital stage 3 or greater of 3.01 and 1.52 respectively, while a twofold increase in the sum of three PCB congeners was associated with an increased odds ratio of 2.98. In a Russian cohort of 499 boys followed annually, analysis revealed a trend toward earlier pubertal onset (genital stage 2 or testicular volume $>3 \mathrm{ml}$ ) with increasing PCB exposures (Korrick et al. 2011). Thus, childhood exposures to the environmental contaminants, $\mathrm{HCB}, \mathrm{DDE}$, and $\mathrm{PCB}$, are associated with earlier pubertal milestones in boys.

Published by Bioscientifica Ltd 


\section{EDCs causing delayed pubertal development}

The association of EDCs with pubertal delay has been observed in both girls and boys. Among 138 Akwesasne Mohawk Nation girls living in a heavily contaminated area along the St Lawrence River, those with lead levels above the median $(1.2 \mu \mathrm{g} / \mathrm{dl})$ had menarche 10 months later than those with lower levels (12.7 vs 11.8 years; Denham et al. 2005). The association of lead with pubertal delay in girls has been confirmed using the NHANES III database; blood lead levels of $3 \mu \mathrm{g} / \mathrm{dl}$ compared with $1 \mu \mathrm{g} / \mathrm{dl}$ corresponded to delays in reaching all Tanner stages of breast development (Selevan et al. 2003). Lead is also associated with delay in pubertal onset in boys as shown initially in the cross-sectional Russian Children's study of 489 Russian boys. In this cohort, 8- to 9-year-old boys with blood lead levels $\geq 5 \mu \mathrm{g} / \mathrm{dl}$ were less likely to have onset of puberty assessed by testicular volume than those with lower lead levels (Hauser et al. 2008). Subsequent analysis of longitudinal data in these Russian boys showed that the delay in pubertal onset with blood lead levels $\geq 5 \mu \mathrm{g} / \mathrm{dl}$ was $\sim 6-8$ months (Williams et al. 2010). These studies confirm low-level effects of childhood lead exposures on male and female pubertal timing.

Endosulfan is an insecticide that disrupts spermatogenesis in experimental animals. To explore its effects on pubertal development, the sexual maturity rating of 117 boys living in the foothills of cashew plantations sprayed regularly with endosulfan was compared with 90 unexposed controls (Saiyed et al. 2003). The exposed boys had lower sexual maturity rating scores and serum testosterone concentrations than controls, while serum LH was higher, suggesting inhibition of androgen synthesis or decreased responsiveness of the testicular Leydig cells.

The aromatic hydrocarbons include dioxins and dioxinlike compounds that are generated during industrial processes and industrial chemicals such as PCBs that are currently banned but persist in the environment. One method of quantifying the relative AHR-mediated toxicity of these compounds is to determine toxic equivalency (TEQs) in comparison with a highly potent reference compound, TCDD. A Flemish group examined the reproductive effects of exposures to PCBs and dioxin-like compounds in a group of 200 teenagers, ages 15-19 years (Den Hond et al. 2002). They compared sexual maturity stage, testicular volume, and hormone profiles in boys from two contaminated suburbs vs a non-industrialized rural area. The authors estimated PCB exposure based upon measurement of three PCB congeners and an AHR-luciferase cellular assay (CALUX) for dioxin bioactivity. Ninety-two percent of boys living in the less-contaminated suburb and $100 \%$ of the rural boys were sexually mature compared with $62 \%$ of the boys living in the suburb with two waste incinerators. Testicular volumes of boys living in either suburb were smaller compared with that of rural boys. A doubling of serum PCB 138 concentrations was associated with a 3.5 odds of being in earlier stages of puberty. An ongoing longitudinal cohort study is following pubertal onset and progression by physician examination in relation to measured peripubertal organochlorine, pesticide, and heavy metal concentrations in 489 boys residing in Chapaevsk, Russia (Korrick et al. 2011). At ages 8-9 years, the median serum TEQ concentration was $21 \mathrm{pg} / \mathrm{g}$ lipid (range of 4-175), approximately threefold higher than in European children. In this cohort, higher dioxin TEQs, and serum TCDD and dioxin concentrations, were associated with later pubertal onset, defined as testicular volume $>3 \mathrm{ml}$. The highest quartile of TCDD concentrations was associated with a delay in attainment of pubertal onset by 5.5 months.

Several groups have examined the effects of EDCs on sex steroid and gonadotropin concentrations in children and adolescents living in contaminated areas (Hsu et al. 2005, Dhooge et al. 2009, English et al. 2012). Dhooge et al. (2009) examined the associations of measured EDC exposures on sex steroid concentrations in 887 14- and 15 -year-old boys living in environmentally contaminated areas of Flanders. After adjustment for confounders, they found a negative association of serum cadmium with testosterone and estradiol $\left(\mathrm{E}_{2}\right)$ concentrations. By contrast, they found a positive association of serum HCB and the sum of PCBs 138, 153, and 180 with serum concentrations of testosterone and $\mathrm{E}_{2}$. The authors note that EDC concentrations in their cohort were relatively low and that these associations might reflect low-dose effects. In a cross-sectional study of 177 farm boys exposed to pesticides and 92 controls, the farm boys had lower serum testosterone and $\mathrm{LH}$ values and higher serum $\mathrm{E}_{2}$ levels, suggesting that postnatal childhood exposures could also interfere with normal functioning of the HPG axis (English et al. 2012). The effects of prenatal exposures to non-dioxin-like compounds have been examined in two cohorts. Among 438 adolescent boys from a Faroe Islands birth cohort, prenatal PCB exposures were associated with lower serum LH and testosterone concentrations (Grandjean et al. 2012). A cohort of boys in Taiwan exposed in utero to PCBs and PCDFs have been followed prospectively for health outcomes (Hsu et al. 2005). Of the pubertal boys (older than 13 years), prenatal PCB and PCDF exposures were associated with lower serum testosterone and FSH values. These studies suggest that chemical exposures with endocrine active

Published by Bioscientifica Ltd 
properties may disrupt the HPG axis both centrally and at the end-organ testicular level to cause changes in serum hormone concentrations in exposed vs non-exposed boys without noticeable alterations in pubertal timing.

\section{Conclusions}

This review summarizes the few studies that assess the effects of EDC exposures on male puberty in humans. Several of these reports demonstrate plausible associations of exposures with altered onset of puberty, findings that are consistent with animal data. These findings, in parallel with the observed secular trends in pubertal timing, support a role for environmental chemicals in shifting pubertal development. As yet unknown is whether the changes in pubertal development pose future health risks for infertility or other detrimental reproductive or metabolic outcomes.

While the impact of the population shift in pubertal onset on adult health risks remains to be ascertained, several studies have reported detrimental effects of early puberty in individuals. Early puberty is associated with more rapid epiphyseal maturation that leads to short stature in the adult. Moreover, children with earlier pubertal development are reported to have poor self-image and have an increased risk for substance abuse, risk-taking behaviors, depression, and eating disorders (Golub et al. 2008). Puberty delay has also been associated with increased risk for psychosocial pathology such as being victimized and correlates with risk for eating disorders, depression, and low bone mineralization. Epidemiological data suggest an association of earlier menarche with an increased risk for reproductive cancers. Premature adrenarche has been associated with later obesity, diabetes mellitus, and cardiovascular disease. Additional studies to examine environmental determinants of puberty might identify modifiable factors and yield insight on possible preventive measures to improve adult health.

\section{Declaration of interest}

Drs W Z and M M L declare that there is no conflict of interest that could be perceived as prejudicing the impartiality of the review reported.

\section{Funding}

This review did not receive any specific grant from any funding agency in the public, commercial or not-for-profit sector.

\section{Acknowledgements}

The authors would like to thank Dr Ningning Zhang for her assistance with manuscript editing.

\section{References}

Acerini CL \& Hughes IA 2006 Endocrine disrupting chemicals: a new and emerging public health problem? Archives of Disease in Childhood 91 633-641. (doi:10.1136/adc.2005.088500)

Anderson SE, Dallal GE \& Must A 2003 Relative weight and race influence average age at menarche: results from two nationally representative surveys of US girls studied 25 years apart. Pediatrics 111 844-850. (doi:10.1542/peds.111.4.844)

Bell DR, Clode S, Fan MQ, Fernandes A, Foster PM, Jiang T, Loizou G, MacNicoll A, Miller BG, Rose M et al. 2007 Toxicity of 2,3,7,8-tetrachlorodibenzo-p-dioxin in the developing male Wistar (Han) rat. II: chronic dosing causes developmental delay. Toxicological Sciences 99 224-233. (doi:10.1093/toxsci/kfm141)

Biro FM, Lucky AW, Huster GA \& Morrison JA 1990 Hormonal studies and physical maturation in adolescent gynecomastia. Journal of Pediatrics 116 450-455. (doi:10.1016/S0022-3476(05)82843-4)

Biro FM, Galvez MP, Greenspan LC, Succop PA, Vangeepuram N, Pinney SM, Teitelbaum S, Windham GC, Kushi LH \& Wolff MS 2010 Pubertal assessment method and baseline characteristics in a mixed longitudinal study of girls. Pediatrics 126 e583-e590. (doi:10.1542/ peds.2009-3079)

Biro FM, Greenspan LC \& Galvez MP 2012 Puberty in girls of the 21st century. Journal of Pediatric and Adolescent Gynecology 25 289-294. (doi:10.1016/j. jpag.2012.05.009)

Bordini B \& Rosenfield RL 2011 Normal pubertal development: part II: clinical aspects of puberty. Pediatrics in Review 32 281-292. (doi:10.1542/pir.32-7-281)

Carson R 1962. In Silent Spring. Boston: Houghton Mifflin.

Cooke GM, Price CA \& Oko RJ 1998 Effects of in utero and lactational exposure to 2,3,7,8-tetrachlorodibenzo-p-dioxin (TCDD) on serum androgens and steroidogenic enzyme activities in the male rat reproductive tract. Journal of Steroid Biochemistry and Molecular Biology 67 347-354. (doi:10.1016/S0960-0760(98)00127-7)

Crofton PM, Evans AE, Wallace AM, Groome NP \& Kelnar CJ 2004 Nocturnal secretory dynamics of inhibin $B$ and testosterone in pre- and peripubertal boys. Journal of Clinical Endocrinology and Metabolism 89 867-874. (doi:10.1210/jc.2003-030884)

Den Hond E, Roels HA, Hoppenbrouwers K, Nawrot T, Thijs L, Vandermeulen C, Winneke G, Vanderschueren D \& Staessen JA 2002 Sexual maturation in relation to polychlorinated aromatic hydrocarbons: Sharpe and Skakkebaek's hypothesis revisited. Environmental Health Perspectives 110 771-776. (doi:10.1289/ehp.02110771)

Den Hond E, Dhooge W, Bruckers L, Schoeters G, Nelen V, van de Mieroop E, Koppen G, Bilau M, Schroijen C, Keune H et al. 2010 Internal exposure to pollutants and sexual maturation in Flemish adolescents. Journal of Exposure Science and Environmental Epidemiology 21 224-233. (doi:10.1038/jes.2010.2)

Denham M, Schell LM, Deane G, Gallo MV, Ravenscroft J \& DeCaprio AP 2005 Relationship of lead, mercury, mirex, dichlorodiphenyldichloroethylene, hexachlorobenzene, and polychlorinated biphenyls to timing of menarche among Akwesasne Mohawk girls. Pediatrics 115 e127-e134. (doi:10.1542/peds.2004-1161)

Dhooge W, Den Hond E, Koppen G, Bruckers L, Nelen V, van de Mieroop E, Bilau M, Croes K, Baeyens W, Schoeters G et al. 2009 Internal exposure to pollutants and sex hormone levels in Flemish male adolescents in a cross-sectional study: associations and dose-response relationships. Journal of Exposure Science and Environmental Epidemiology 21 224-233. (doi: 10.1038/jes.2009.63)

Diamanti-Kandarakis E, Bourguignon JP, Giudice LC, Hauser R, Prins GS, Soto AM, Zoeller RT \& Gore AC 2009 Endocrine-disrupting chemicals: an Endocrine Society scientific statement. Endocrine Reviews $\mathbf{3 0}$ 293-342. (doi:10.1210/er.2009-0002)

Dickerson SM \& Gore AC 2007 Estrogenic environmental endocrinedisrupting chemical effects on reproductive neuroendocrine function 
and dysfunction across the life cycle. Reviews in Endocrine \& Metabolic Disorders 8 143-159. (doi:10.1007/s11154-007-9048-y)

Dolinoy DC, Weidman JR \& Jirtle RL 2007 Epigenetic gene regulation: linking early developmental environment to adult disease. Reproductive Toxicology 23 297-307. (doi:10.1016/j.reprotox.2006.08.012)

Durrer S, Ehnes C, Fuetsch M, Maerkel K, Schlumpf M \& Lichtensteiger W 2007 Estrogen sensitivity of target genes and expression of nuclear receptor co-regulators in rat prostate after pre- and postnatal exposure to the ultraviolet filter 4-methylbenzylidene camphor. Environmental Health Perspectives 115(Suppl 1) 42-50. (doi: 10.1289/ehp.9134)

Ebling FJ 2005 The neuroendocrine timing of puberty. Reproduction 129 675-683. (doi:10.1530/rep.1.00367)

English RG, Perry M, Lee MM, Hoffman E, Delport S \& Dalvie MA 2012 Farm residence and reproductive health among boys in rural South Africa. Environment International 47 73-79. (doi:10.1016/j.envint. 2012.06.006)

Euling SY, Herman-Giddens ME, Lee PA, Selevan SG, Juul A, Sorensen TI, Dunkel L, Himes JH, Teilmann G \& Swan SH 2008a Examination of US puberty-timing data from 1940 to 1994 for secular trends: panel findings. Pediatrics 121(Suppl 3) S172-S191. (doi:10.1542/peds. 2007-1813D)

Euling SY, Selevan SG, Pescovitz OH \& Skakkebaek NE $2008 b$ Role of environmental factors in the timing of puberty. Pediatrics 121(Suppl 3) S167-S171. (doi:10.1542/peds.2007-1813C)

Forest MG, Cathiard AM \& Bertrand JA 1973 Evidence of testicular activity in early infancy. Journal of Clinical Endocrinology and Metabolism 37 148-151. (doi:10.1210/jcem-37-1-148)

Ge RS, Chen GR, Dong Q, Akingbemi B, Sottas CM, Santos M, Sealfon SC, Bernard DJ \& Hardy MP 2007 Biphasic effects of postnatal exposure to diethylhexylphthalate on the timing of puberty in male rats. Journal of Andrology 28 513-520. (doi:10.2164/jandrol.106.001909)

Gladen BC, Ragan NB \& Rogan WJ 2000 Pubertal growth and development and prenatal and lactational exposure to polychlorinated biphenyls and dichlorodiphenyl dichloroethene. Journal of Pediatrics 136 490-496. (doi:10.1016/S0022-3476(00)90012-X)

Golub MS, Collman GW, Foster PM, Kimmel CA, Rajpert-De Meyts E, Reiter EO, Sharpe RM, Skakkebaek NE \& Toppari J 2008 Public health implications of altered puberty timing. Pediatrics 121(Suppl 3) S218-S230. (doi:10.1542/peds.2007-1813G)

Grandjean P, Gronlund C, Kjaer IM, Jensen TK, Sorensen N, Andersson AM, Juul A, Skakkebaek NE, Budtz-Jorgensen E \& Weihe P 2012 Reproductive hormone profile and pubertal development in 14-year-old boys prenatally exposed to polychlorinated biphenyls. Reproductive Toxicology 34 498-503. (doi:10.1016/j.reprotox.2012.07.005)

Gray LE Jr, Ostby J, Ferrell J, Rehnberg G, Linder R, Cooper R, Goldman J, Slott V \& Laskey J 1989 A dose-response analysis of methoxychlorinduced alterations of reproductive development and function in the rat. Fundamental and Applied Toxicology 12 92-108. (doi:10.1016/ 0272-0590(89)90065-1)

Grumbach MM 2002 The neuroendocrinology of human puberty revisited. Hormone Research 57(Suppl 2) 2-14. (doi:10.1159/000058094)

Hamm JT, Chen CY \& Birnbaum LS 2003 A mixture of dioxins, furans, and non-ortho PCBs based upon consensus toxic equivalency factors produces dioxin-like reproductive effects. Toxicological Sciences $\mathbf{7 4}$ 182-191. (doi:10.1093/toxsci/kfg107)

Harlan WR, Grillo GP, Cornoni-Huntley J \& Leaverton PE 1979 Secondary sex characteristics of boys 12 to 17 years of age: the U.S. Health Examination Survey. Journal of Pediatrics 95 293-297. (doi:10.1016/ S0022-3476(79)80679-4)

Hauser R, Sergeyev O, Korrick S, Lee MM, Revich B, Gitin E, Burns JS \& Williams PL 2008 Association of blood lead levels with onset of puberty in Russian boys. Environmental Health Perspectives 116 976-980. (doi:10.1289/ehp.10516)

Herbst AL, Ulfelder H \& Poskanzer DC 1971 Adenocarcinoma of the vagina. Association of maternal stilbestrol therapy with tumor appearance in young women. New England Journal of Medicine 284 878-881. (doi:10.1056/NEJM197104222841604)

Herman-Giddens ME, Slora EJ, Wasserman RC, Bourdony CJ, Bhapkar MV, Koch GG \& Hasemeier CM 1997 Secondary sexual characteristics and menses in young girls seen in office practice: a study from the Pediatric Research in Office Settings network. Pediatrics 99 505-512. (doi:10.1542/peds.99.4.505)

Herman-Giddens ME, Wang L \& Koch G 2001 Secondary sexual characteristics in boys: estimates from the national health and nutrition examination survey III, 1988-1994. Archives of Pediatrics \& Adolescent Medicine 155 1022-1028.

Hsu PC, Lai TJ, Guo NW, Lambert GH \& Leon Guo Y 2005 Serum hormones in boys prenatally exposed to polychlorinated biphenyls and dibenzofurans. Journal of Toxicology and Environmental Health. Part A 68 1447-1456. (doi:10.1080/ 15287390590967360)

Jacobson-Dickman E \& Lee MM 2009 The influence of endocrine disruptors on pubertal timing. Current Opinion in Endocrinology, Diabetes, and Obesity 16 25-30. (doi:10.1097/MED.0b013e328320d560)

Karpati AM, Rubin CH, Kieszak SM, Marcus M \& Troiano RP 2002 Stature and pubertal stage assessment in American boys: the 1988-1994 Third National Health and Nutrition Examination Survey. Journal of Adolescent Health 30 205-212. (doi:10.1016/ S1054-139X(01)00320-2)

Kauffman AS 2010 Coming of age in the kisspeptin era: sex differences, development, and puberty. Molecular and Cellular Endocrinology 5 51-63. (doi:10.1016/j.mce.2010.01.017)

Korrick SA, Lee MM, Williams PL, Sergeyev O, Burns JS, Patterson DG, Turner WE, Needham LL, Altshul L, Revich B et al. 2011 Dioxin exposure and age of pubertal onset among Russian boys. Environmental Health Perspectives 119 1339-1344. (doi:10.1289/ehp. 1003102)

Kulin HE, Frontera MA, Demers LM, Bartholomew MJ \& Lloyd TA 1989 The onset of sperm production in pubertal boys. Relationship to gonadotropin excretion. American Journal of Diseases of Children 143 190-193.

Lee JM, Kaciroti N, Appugliese D, Corwyn RF, Bradley RH \& Lumeng JC $2010 a$ Body mass index and timing of pubertal initiation in boys. Archives of Pediatrics \& Adolescent Medicine 164 139-144. (doi:10.1001/ archpediatrics.2009.258)

Lee PA, Gollenberg AL, Hediger ML, Himes JH, Zhang Z \& Louis GM $2010 b$ Luteinizing hormone, testosterone and inhibin B levels in the peripubertal period and racial/ethnic differences among boys aged 6-11 years: analyses from NHANES III, 1988-1994. Clinical Endocrinology 73 744-751. (doi:10.1111/j.1365-2265.2010.03866.x)

Leijs MM, Koppe JG, Olie K, van Aalderen WM, Voogt P, Vulsma T, Westra M \& ten Tusscher GW 2008 Delayed initiation of breast development in girls with higher prenatal dioxin exposure; a longitudinal cohort study. Chemosphere 73 999-1004. (doi:10.1016/ j.chemosphere.2008.05.053)

Marshall WA \& Tanner JM 1970 Variations in the pattern of pubertal changes in boys. Archives of Disease in Childhood 45 13-23. (doi:10.1136/adc.45.239.13)

Massart F, Seppia P, Pardi D, Lucchesi S, Meossi C, Gagliardi L, Liguori R, Fiore L, Federico G \& Saggese G 2005 High incidence of central precocious puberty in a bounded geographic area of northwest Tuscany: an estrogen disrupter epidemic? Gynecological Endocrinology 20 92-98. (doi:10.1080/09513590400021060)

Monosson E, Kelce WR, Lambright C, Ostby J \& Gray LE Jr 1999 Peripubertal exposure to the antiandrogenic fungicide, vinclozolin, delays puberty, inhibits the development of androgen-dependent tissues, and alters androgen receptor function in the male rat. Toxicology and Industrial Health 15 65-79.

Mouritsen A, Aksglaede L, Sorensen K, Mogensen SS, Leffers H, Main KM, Frederiksen H, Andersson AM, Skakkebaek NE \& Juul A 2010 Hypothesis: exposure to endocrine-disrupting chemicals may interfere 
with timing of puberty. International Journal of Andrology 33 346-359. (doi:10.1111/j.1365-2605.2010.01051.x)

Navarro VM, Sanchez-Garrido MA, Castellano JM, Roa J, Garcia-Galiano D, Pineda R, Aguilar E, Pinilla L \& Tena-Sempere M 2009 Persistent impairment of hypothalamic KiSS-1 system after exposures to estrogenic compounds at critical periods of brain sex differentiation. Endocrinology 150 2359-2367. (doi:10.1210/en.2008-0580)

Nebesio TD \& Pescovitz O 2005 Historical perspectives: endocrine disruptors and the timing of puberty. Endocrinologist 15 44-48. (doi:10.1097/01.ten.0000152722.38643.58)

Nielsen CT, Skakkebaek NE, Darling JA, Hunter WM, Richardson DW, Jorgensen M \& Keiding N 1986 Longitudinal study of testosterone and luteinizing hormone (LH) in relation to spermarche, pubic hair, height and sitting height in normal boys. Acta Endocrinologica. Supplementum 279 98-106.

Oakley AE, Clifton DK \& Steiner RA 2009 Kisspeptin signaling in the brain. Endocrine Reviews 30 713-743. (doi:10.1210/er.2009-0005)

Odum J, Lefevre PA, Tinwell H, Van Miller JP, Joiner RL, Chapin RE, Wallis NT \& Ashby J 2002 Comparison of the developmental and reproductive toxicity of diethylstilbestrol administered to rats in utero, lactationally, preweaning, or postweaning. Toxicological Sciences $\mathbf{6 8}$ 147-163. (doi:10.1093/toxsci/68.1.147)

Ojeda SR, Dubay C, Lomniczi A, Kaidar G, Matagne V, Sandau US \& Dissen GA 2010 Gene networks and the neuroendocrine regulation of puberty. Molecular and Cellular Endocrinology 324 3-11. (doi:10.1016/ j.mce.2009.12.003)

Patisaul H \& Adewale H 2009 Long-term effects of environmental endocrine disruptors on reproductive physiology and behavior. Frontiers in Behavioral Neuroscience 3 10. (doi:10.3389/neuro.08. $010.2009)$

Rasier G, Toppari J, Parent AS \& Bourguignon JP 2006 Female sexual maturation and reproduction after prepubertal exposure to estrogens and endocrine disrupting chemicals: a review of rodent and human data. Molecular and Cellular Endocrinology 254-255 187-201. (doi:10.1016/j.mce.2006.04.002)

Rockett JC, Lynch CD \& Buck GM 2004 Biomarkers for assessing reproductive development and health: part 1 - pubertal development. Environmental Health Perspectives 112 105-112. (doi:10.1289/ehp.6265)

Rogol AD 2010 Sex steroids, growth hormone, leptin and the pubertal growth spurt. Endocrine Development 17 77-85. (doi: 10.1159/ 000262530)

Roseweir AK \& Millar RP 2009 The role of kisspeptin in the control of gonadotrophin secretion. Human Reproduction Update 15 203-212. (doi:10.1093/humupd/dmn058)

Saiyed H, Dewan A, Bhatnagar V, Shenoy U, Shenoy R, Rajmohan H, Patel K, Kashyap R, Kulkarni P, Rajan B et al. 2003 Effect of endosulfan on male reproductive development. Environmental Health Perspectives 111 1958-1962. (doi:10.1289/ehp.6271)

Schoeters G, Den Hond E, Dhooge W, van Larebeke N \& Leijs M 2008 Endocrine disruptors and abnormalities of pubertal development. Basic Clinical Pharmacology \& Toxicology 102 168-175. (doi:10.1111/ j.1742-7843.2007.00180.x)

Selevan SG, Rice DC, Hogan KA, Euling SY, Pfahles-Hutchens A \& Bethel J 2003 Blood lead concentration and delayed puberty in girls. New England Journal of Medicine 348 1527-1536. (doi:10.1056/ NEJMoa020880)

Sharpe RM \& Skakkebaek NE 1993 Are oestrogens involved in falling sperm counts and disorders of the male reproductive tract? Lancet $\mathbf{3 4 1}$ 1392-1395. (doi:10.1016/0140-6736(93)90953-E)
Shin JH, Kim TS, Kang IH, Kang TS, Moon HJ \& Han SY 2009 Effects of postnatal administration of diethylstilbestrol on puberty and thyroid function in male rats. Journal of Reproduction and Development 55 461-466. (doi:10.1262/jrd.20169)

Sorensen K, Mouritsen A, Aksglaede L, Hagen CP, Mogensen SS \& Juul A 2012 Recent secular trends in pubertal timing: implications for evaluation and diagnosis of precocious puberty. Hormone Research in Paediatrics 77 137-145. (doi:10.1159/000336325)

Strom BL, Schinnar R, Ziegler EE, Barnhart KT, Sammel MD, Macones GA, Stallings VA, Drulis JM, Nelson SE \& Hanson SA 2001 Exposure to soy-based formula in infancy and endocrinological and reproductive outcomes in young adulthood. Journal of the American Medical Association 286 807-814. (doi:10.1001/jama.286.7.807)

Su PH, Huang PC, Lin CY, Ying TH, Chen JY \& Wang SL 2012 The effect of in utero exposure to dioxins and polychlorinated biphenyls on reproductive development in eight year-old children. Environment International 39 181-187. (doi:10.1016/j.envint. 2011.09.009)

Sun SS, Schubert CM, Liang R, Roche AF, Kulin HE, Lee PA, Himes JH \& Chumlea WC 2005 Is sexual maturity occurring earlier among U.S. children? Journal of Adolescent Health 37 345-355. (doi:10.1016/ j.jadohealth.2004.10.009)

Tan BL, Kassim NM \& Mohd MA 2003 Assessment of pubertal development in juvenile male rats after sub-acute exposure to bisphenol A and nonylphenol. Toxicology Letters 143 261-270. (doi:10.1016/ S0378-4274(03)00172-3)

Tanner JM 1985 Growth regulation and the genetics of growth. Progress in Clinical and Biological Research 200 19-32.

Tena-Sempere M 2010 Kisspeptin/GPR54 system as a potential target for endocrine disruption of reproductive development and function. International Journal of Andrology 33 360-368. (doi:10.1111/ j.1365-2605.2009.01012.x)

Terasawa E \& Fernandez DL 2001 Neurobiological mechanisms of the onset of puberty in primates. Endocrine Reviews 22 111-151. (doi:10.1210/ er.22.1.111)

Toppari J \& Juul A 2010 Trends in puberty timing in humans and environmental modifiers. Molecular and Cellular Endocrinology 324 39-44. (doi:10.1016/j.mce.2010.03.011)

Walker DM \& Gore AC 2011 Transgenerational neuroendocrine disruption of reproduction. Nature Reviews. Endocrinology 7 197-207. (doi:10.1038/ nrendo.2010.215)

Walvoord EC 2010 The timing of puberty: is it changing? Does it matter? Journal of Adolescent Health 47 433-439. (doi:10.1016/j.jadohealth. 2010.05.018)

Williams PL, Sergeyev O, Lee MM, Korrick SA, Burns JS, Humblet O, DelPrato J, Revich B \& Hauser R 2010 Blood lead levels and delayed onset of puberty in a longitudinal study of Russian boys. Pediatrics $\mathbf{1 2 5}$ e1088-e1096. (doi:10.1542/peds.2009-2575)

Yoshimura S, Yamaguchi H, Konno K, Ohsawa N, Noguchi S \& Chisaka A 2005 Observation of preputial separation is a useful tool for evaluating endocrine active chemicals. Journal of Toxicologic Pathology 18 141-157. (doi:10.1293/tox.18.141)

Zoeller RT, Brown TR, Doan LL, Gore AC, Skakkebaek NE, Soto AM, Woodruff TJ \& Vom Saal FS 2012 Endocrine-disrupting chemicals and public health protection: a statement of principles from the endocrine society. Endocrinology 153 4097-4110. (doi:10.1210/ en.2012-1422)

Received in final form 23 May 2013

Accepted 24 May 2013

Accepted Preprint published online 24 May 2013 http://joe.endocrinology-journals.org DOI: 10.1530/JOE-12-0449
() 2013 Society for Endocrinology Printed in Great Britain
Published by Bioscientifica Ltd 